\title{
Synthetic Calcium Phosphate Ceramics for Treatment of Bone Fractures
}

\author{
Nicola Döbelin*, Reto Luginbühl, and Marc Bohner
}

\begin{abstract}
Bone is a complex natural material with outstanding mechanical properties and remarkable self-healing capabilities. The mechanical strength is achieved by a complex structure of a mineral part comprising apatitic calcium phosphate crystals embedded in an organic matrix. Bone also contains several types of cells constantly replacing mature bone with new bone. These cells are able to seal fractures and fill gaps with new bone in case of structural damage. However, if a defect exceeds a critical size, surgery is necessary to fill the void with a spacer in order to prevent soft tissue from growing into the defect and delaying the healing process. The spacers, also known as bone grafts, can either be made of fresh bone from the patient, of processed bone from donor organisms, or of synthetic materials chemically similar to the mineral part of bone. Synthetic bone void fillers are also known as bone graft substitutes. This review aims at explaining the biological and chemical background that lead to the development of synthetic bone graft substitutes and gives an overview of the current state of development. It also highlights the multidisciplinary nature of biomaterials research, which combines cell biology and medicine with chemistry, mineralogy, crystallography, and mechanical engineering.
\end{abstract}

Keywords: Biomaterial $\cdot$ Bone substitute $\cdot$ Calcium phosphate $\cdot$ Medical device

\section{Introduction}

In millions of years of evolution, Nature has created materials and concepts with remarkable physical and chemical properties. Many modern technologies were originally inspired by natural phenomena, and even nowadays after more than a century of rapid technological advances, Nature provides a rich pool of new concepts inspiring researchers and engineers to develop bio-inspired and bio-mimetic technologies. Examples for unmatched performance of natural systems can be found in many aspects of modern life, including the aerodynamics of certain bird species, ${ }^{[1]}$ hydrodynamics of shark skin, ${ }^{[2]}$ self-cleaning properties of lotus leaves, ${ }^{[3]}$ or the adhesive properties of gecko feet, ${ }^{[4]}$ to name just a few.
*Correspondence: N. Döbelin

RMS Foundation

Bischmattstrasse 12

$\mathrm{CH}-2544$ Bettlach

Tel.: +41326441400

Fax: + 41326441476

E-mail: nicola.doebelin@rms-foundation.ch
Nature has also created highly specialized materials with outstanding mechanical properties. These so-called biological structural materials occur in the form of bone, teeth, tusks, horns, antlers, mollusc shells, sea sponges, diatoms, crab exoskeletons, hooves, claws, bird beaks and insect cuticles, and they serve various purposes such as structural support (bones, mollusc shells, hooves), protection (mollusc shells, bones), mastication (teeth, beaks), as well as defence and aggression (claws, teeth, beaks, tusks, horns, antlers). ${ }^{[5]}$ They must withstand repeated high impact and compressive forces throughout the life-span of the organism. Therefore, they have developed mechanical properties still unmatched by synthetic materials. In fact, bone has a tensile strength similar to that of cast iron, but it is three times lighter and ten times more flexible. ${ }^{[6]}$ The hierarchical features responsible for outstanding fracture resistance range from the nano- to the macroscale and are complex and challenging to replicate in synthetic materials. ${ }^{[7]}$

Bone is a highly organized tissue that is hierarchically arranged at the nano(molecular), micro- (cellular), and macro-scale (tissue level) in two and three dimensions. The organization starts at the nano-scale with the molecular folding and arrangement of collagenous proteins forming an organic matrix in the form of strong fibre bundles. The matrix is reinforced with a mineral phase of apatite nano-crystals. At the microscopic or cellular level, the organic and mineral phase arrange into two forms of bone tissue: woven, or primary, bone and lamellar bone. Woven bone is an isotropic tissue with coarse collagen fibres which are randomly oriented. Lamellar bone is formed from woven bone during the remodelling process. It is highly anisotropic and stress oriented, i.e. the tissue organization adapts and depends on the applied forces. Both woven and lamellar bone are macroscopically organized into trabecular or cortical bone. Trabecular bone, also known as spongy or cancellous bone, forms a complex three-dimensional scaffold whose lattice is optimized and aligned as a response to the complex stress and strain observed at the macroscopic level. Cortical bone is a dense and compact material. It embraces the trabecular bone like a hull to protect the delicate trabecular scaffold from impact. Cortical bone is subject to bending, torsional and compressive forces. While cortical bone has four times the density of trabecular bone, its metabolic turnover is eight times lower.

The total mineral part constitutes 60 $70 \%$ of the dry weight of mature bone. ${ }^{[8]}$ It imparts hardness and stiffness, while the organic part increases the bone's toughness and resilience. ${ }^{[9]}$ The different contributions of the organic and mineral components to the mechanical properties are readily demonstrated by bones that have been demineralised or have had their organic matrix removed. The original shape and size of the bone is retained by both procedures, but the mechanical properties are altered greatly. Demineralised bone is flexible, pliable, and fracture resistant like a piece of tough rubber. If the organic component is extracted, the mineralized 
skeleton of the bone becomes brittle and fractures easily. ${ }^{[10]}$

\section{Bone Cells}

Bone cells responsible for bone formation, resorption, and repair, as well as for mineral homeostasis originate from sources, the mesenchymal and the hematopoietic progenitor or stem cells. ${ }^{[6]}$ Proliferation and differentiation into specialized phenotypes of bone cells are stimulated by the release of various growth and transcription factors, hormones, and by mechanical stimuli. Bone is constantly dissolved and replaced in a process known as bone remodelling. Cells responsible for bone resorption are osteoclasts, ${ }^{[11]}$ bone-forming cells are osteoblasts. ${ }^{[12]}$ In a healthy adult person dissolution and formation rates are in equilibrium, leading to a roughly constant mass of bone over time. However, dysfunction of either process may lead to excessive bone formation (osteopetrosis, osteosclerosis) or bone degradation (osteoporosis), respectively.

In order to resorb and replace bone, osteoclasts migrate along the bone matrix and adhere to the surface forming a sealed zone between the cell and the bone matrix, which defines the perimeter to be resorbed. Release of acids decreases the $\mathrm{pH}$ from 7 to approximately $4.7,[13]$ which dissolves the mineral constituents of the bone. The organic matrix is dissolved by secretion of hydrolytic enzymes. Once a resorption lacuna has been formed and the resorption process has been completed, the osteoclasts migrate forward to adjacent locations without detaching from the surface maintaining the sealed zone by the ruffled border. ${ }^{[14]}$

Osteoblasts are responsible for the synthesis and secretion of the bone matrix. They are located behind the osteoclasts in the resorption area during remodeling. A uncalcified zone, the osteoid, is found between the cell and the calcified bone matrix. During calcification, calcium phosphate ions from the extra cellular fluids mineralize in the osteoid, but the osteoblast cells always remain separated from the bone by a new osteoid layer. As the secreted matrix accumulates, some of the osteoblasts surround themselves with organic matrix and become mature bone cells, also known as osteocytes. The cavity occupied by osteocytes is known as the lacuna, and although osteocytes appear to be inactive, they continue secreting substances necessary to maintain the surrounding calcified bone. ${ }^{[10]}$

\section{Bone Mineral}

The principle mineral constituent of mature bone is poorly crystalline non-stoi- chiometric hydroxyapatite with a crystal size of approximately $40 \mathrm{~nm}$ in length, 25 $\mathrm{nm}$ in width, and $1.5-3 \mathrm{~nm}$ in thickness. ${ }^{[10]}$ The small crystallite size and the complex chemical composition, which is far from stoichiometric hydroxyapatite, have been major reasons for the difficulties in determining the crystal structure of bone mineral.[15] Biologically formed nanocrystallites lead to broad reflections in Xray diffraction patterns and to an inherent non-stoichiometric composition. ${ }^{[16]}$ Furthermore, substantial substitutions of $\mathrm{CO}_{3}{ }^{2-}$, citrate, $\mathrm{Mg}^{2+}$, and $\mathrm{Na}^{+}$, as well as trace amounts of $\mathrm{Cl}^{-}, \mathrm{F}^{-}, \mathrm{K}^{+}$, and $\mathrm{Sr}^{2+}$ were found in addition to $\mathrm{Ca}$-deficiency and a variable $\mathrm{OH}^{-}$content. ${ }^{[17]}$ Bone minerals store approximately $99 \%$ of the body calcium, $85 \%$ of the phosphorous, and $40-60 \%$ of the total body magnesium and sodium. By serving as a reservoir for these ions, the inorganic bone matrix regulates their concentration in the extracellular fluid in a range necessary for important physiological functions such as nerve conduction, muscle contraction, as well as most of the important biochemical reactions. ${ }^{[18]}$

The crystallisation processes eventually resulting in biological apatite have been subject of controversial discussions for a long time. After mineralization, the density of the young bone is low. At the same time, the degree of crystallinity of bone minerals is so poor that it barely produces a discrete X-ray diffraction (XRD) pattern, and the molar ratio of calcium and phosphorous $(\mathrm{Ca}: \mathrm{P}$ ratio) in the mineral is far below stoichiometric apatite. As the bone matures, the density increases, crystals grow, and the $\mathrm{Ca}: \mathrm{P}$ ratio increases, however without reaching a ratio of 1.67 as it would be required for stoichiometric hydroxyapatite. ${ }^{[19]}$ It is now generally agreed that the first solid phase initially precipitating from the oversaturated extracellular fluid is an unstable amorphous calcium phosphate (ACP), which transforms to more stable phases. It was proposed that the subsequent crystallisation sequence forms precursor phases, namely octacalcium phosphate (OCP) and/or brushite (DCPD), which hydrolyze to apatite. Other theories suggest that biological apatite directly crystallizes from ACP without formation of precursor phases. ${ }^{[8,15,19-21]}$ The situation is further complicated by the fact that i) the crystallinity is extremly poor for all phases involved in early stages of the mineralization, ii) the life-time of transient phases may be too short for most analytical techniques, and iii) the crystallization sequence is very sensitive to the ionic composition and the $\mathrm{pH}$ of the surrounding medium. Varying results are thus obtained from healthy bone, pathological calcifications of dead bone, and in vitro experiments.

\section{Fractures}

Bone tissue can be injured and damaged by a multitude of causes at any organizational level. It may be due to physiological disorders, infection, or mechanical impact. Bone tissue that is mechanically damaged, e.g. by fracturing, fortunately exhibits most often a very high self-healing capacity. Reparative response is immediately initiated after damage by local hyperemia and blood clotting. In the first inflammation stage, macrophages, neutrophils and monocytes appear at the site of injury. Revascularization is of utmost importance since bone is a highly vascular tissue. Subsequently, mesenchymal progenitor cells are recruited which will differentiate to bone-forming osteoblast cells. In addition, bone-resorbing osteoclast cells are differentiated from the hematopoietic progenitor cells. There is only little knowledge on the exact stimulating factors that initiate osteoblast and osteoclast recruitment. The recruited cells immediately begin with fibrous and cartilaginous tissue formation which leads to the formation of a so-called soft callus. Soft callus formation helps to stabilize the bony fragments. During that period, vascularity increases and the cartilaginous soft callus is continuously converted to woven bone by mineralization of the tissue which creates a solid connection between the bony fragments. Finally, the new woven bone is slowly remodelled and converted to lamellar bone.

Sometimes local, systemic, or environmental factors prevent successful fracture repair. Local factors may include extensive soft tissue damage around the fracture site interrupting blood supply, continuous motion between the bone fragments, or the presence of an infection. The self-healing capacity of bone repair also fails or is greatly slowed down when large segments or quantities of bone are missing. The situation when bony bridging is delayed or does not occur is called delayed union or non-union. Both phenomena are characterized at the pathological level by the presence of a gap filled by soft tissue only. The risk for non-unions can be greatly reduced if a defect is filled with a graft to which new bone can bond. These spacers, or bone void fillers, reduce the distance in the defect to be bridged and prevent the ingrowth of soft tissue.

\section{Bone Grafts}

Bone grafts used to fill large bone defects can be obtained from a variety of natural or synthetic sources. Despite advances in the development of non-autologous alternatives, autologous bone grafts (autograft) are still considered as the gold standard by 
many clinicians. Autografts are made from the patient's own bone and/or bone marrow harvested intraoperatively from a donor site, typically from the iliac crest, crushed and mixed with blood to form a paste. Bone cells in the autograft that survive the transplant contribute to immediate bone formation, mainly during the first four weeks after transplantation. Cancellous bone autograft is easily re-vascularised and rapidly incorporated into the recipient site, but it does not provide any structural support. Autologous cortical graft, either vascularised or non-vascularised, provides excellent structural support and fast healing. All types of autograft are osteoconductive and osteoinductive, i.e. they serve as a scaffold for cells from the surrounding tissue to migrate into the graft and grow and divide (osteoconduction), and they have the potential to bridge critical size defects that would otherwise not regenerate and heal (osteoinduction). ${ }^{[22]}$ Despite their excellent success rate and low risk of rejection and transmission of diseases, autografts are only available in limited quantities, and post-operative complications frequently occur at the donor site. ${ }^{[23,24]}$

The problems of limited supply and the need for a second operation can be avoided by using bone grafts from other natural sources, for example from human cadavers or donors (allograft), or from other species, namely animals (xenograft). However, aggressive chemical treatment is necessary to sterilize and deactivate proteins in order to eliminate the risk for transmission of diseases from donor to recipient. These processes also remove most of the osteoinductive proteins and growth factors, resulting in a lower osteogenic capacity as compared to autografts, ${ }^{[25]}$ and despite rigorous donor screening and tissue treatment, there is still a remaining risk for viral (HIV, hepatitis) and bacterial infection.[26]

\section{Synthetic Bone Graft Substitutes}

Ever since physicians started to investigate and understand the processes of bone healing there has been a great interest in synthetic substitutes for bone grafts, which, produced under controlled and sterile conditions, promised to be devoid of many of the shortcomings of bone grafts from natural sources.

The first successful application of a degradable synthetic calcium salt for the repair of bone defects was reported more than 100 years ago. ${ }^{[27]}$ During the following decades research mainly focused on calcium sulphates ('plaster of Paris'), ${ }^{[28,29]}$ which appeared to be the most promising inorganic material for the repair of skeletal defects at that time. Early in vivo experiments using various calcium phosphate phases, on the other hand, were less successful. ${ }^{[30-32]}$
It was not until the 1960s that new insights in the nature and formation of the mineral phase of bone and teeth led to an explosion of the number of publications describing the biological processes of bone formation. New materials for filling large-scale defects were evaluated, and the potential of calcium phosphates was recognized. Eventually they emerged as one of the most prominent group of materials for synthetic bone grafts. ${ }^{[33-37]}$ Given that poorly crystalline carbonated HA is the main constituent of bone mineral, it is not surprising that initially the focus had been laid on synthetic HA and chemical variations thereof. However, sintered HA has a very slow degradation rate under physiological conditions, and the bulk of the implant persists in the body for years after the implantation. The higher solubility of $\beta$-tricalcium phosphate $\left(\beta-\mathrm{Ca}_{3}\left(\mathrm{PO}_{4}\right)_{2}\right.$, $\beta$-TCP, isostructural minerals: whitlockite, merrillite), on the other hand, allows for complete resorption of the implant and formation of new bone. ${ }^{[37,38]}$ Recently, a trend towards even more soluble phases such as brushite, ${ }^{[39]}$ octacalcium phosphate, ${ }^{[40]}$ or monetite ${ }^{[41]}$ is observed. A non-exhaustive list of common calcium phosphate phases used in synthetic bone graft substitutes is given in Table 1.

Most calcium phosphate phases can be produced by simple precipitation, solid state, hydration reactions, or by temperature-induced phase transformations. The preparation route is not only relevant for production processes; it also determines important morphological and chemical parameters controlling the phases' in vivo stability and the biological response to the implant. Phases prepared at low temperatures by precipitation or hydration reactions often possess specific surface areas one or two orders of magnitude higher than comparable high-temperature phases. This is mainly due to free idiomorphic crystal growth on the inner and outer surfaces (Fig. 1). Some precipitated phases such as precipitated HA (PHA) and amorphous calcium phosphate (ACP) are amorphous or nano-crystalline after formation and crystallize after prolonged soaking time or further treatment.

Table 1. Overview of common calcium phosphate phases

\begin{tabular}{|c|c|c|c|c|}
\hline Name & Chemical composition & Ca:P ratio & Mineral name & Symbol \\
\hline Monocalcium phosphate & $\mathrm{Ca}\left(\mathrm{H}_{2} \mathrm{PO}_{4}\right)_{2}$ & 0.50 & & MCP, MCPA \\
\hline $\begin{array}{l}\text { Monocalcium phosphate } \\
\text { monohydrate }\end{array}$ & $\mathrm{Ca}\left(\mathrm{H}_{2} \mathrm{PO}_{4}\right)_{2} \cdot \mathrm{H}_{2} \mathrm{O}$ & 0.50 & & MCPM \\
\hline Dicalcium phosphate & $\mathrm{CaHPO}_{4}$ & 1.00 & Monetite & DCP, DCPA \\
\hline $\begin{array}{l}\text { Dicalcium phosphate } \\
\text { dihydrate }\end{array}$ & $\mathrm{CaHPO}_{4} \cdot 2 \mathrm{H}_{2} \mathrm{O}$ & 1.00 & Brushite & DCPD \\
\hline $\begin{array}{l}\beta \text {-Calcium } \\
\text { phyrophosphate }\end{array}$ & $\mathrm{Ca}_{2} \mathrm{P}_{2} \mathrm{O}_{7}$ & 1.00 & & CPP \\
\hline Octacalcium phosphate & $\mathrm{Ca}_{8} \mathrm{H}_{2}\left(\mathrm{PO}_{4}\right)_{6} \cdot 5 \mathrm{H}_{2} \mathrm{O}$ & 1.33 & & OCP \\
\hline $\begin{array}{l}\text { Ca-deficient } \\
\text { hydroxyapatite }\end{array}$ & $\begin{array}{l}\mathrm{Ca}_{10-x}\left(\mathrm{HPO}_{4}\right)_{x}\left(\mathrm{PO}_{4}\right)_{6-x} \\
(\mathrm{OH})_{2-x}\end{array}$ & $1.50-1.67$ & & $\mathrm{CDHA}$ \\
\hline$\beta$-Tricalcium phosphate & $\mathrm{Ca}_{3}\left(\mathrm{PO}_{4}\right)_{2}$ & 1.50 & $\begin{array}{l}\text { Whitlockite, } \\
\text { Merrillite }\end{array}$ & $\beta$-ТСР \\
\hline$\alpha$-Tricalcium phosphate & $\mathrm{Ca}_{3}\left(\mathrm{PO}_{4}\right)_{2}$ & 1.50 & & $\alpha-$ TCP \\
\hline Hydroxyapatite & $\mathrm{Ca}_{5}\left(\mathrm{PO}_{4}\right)_{3} \mathrm{OH}$ & 1.67 & Hydroxyapatite & $\mathrm{HA}$ \\
\hline Tetracalcium phosphate & $\mathrm{Ca}_{4}\left(\mathrm{PO}_{4}\right)_{2} \mathrm{O}$ & 2.00 & Hilgenstockite & TetCP \\
\hline
\end{tabular}
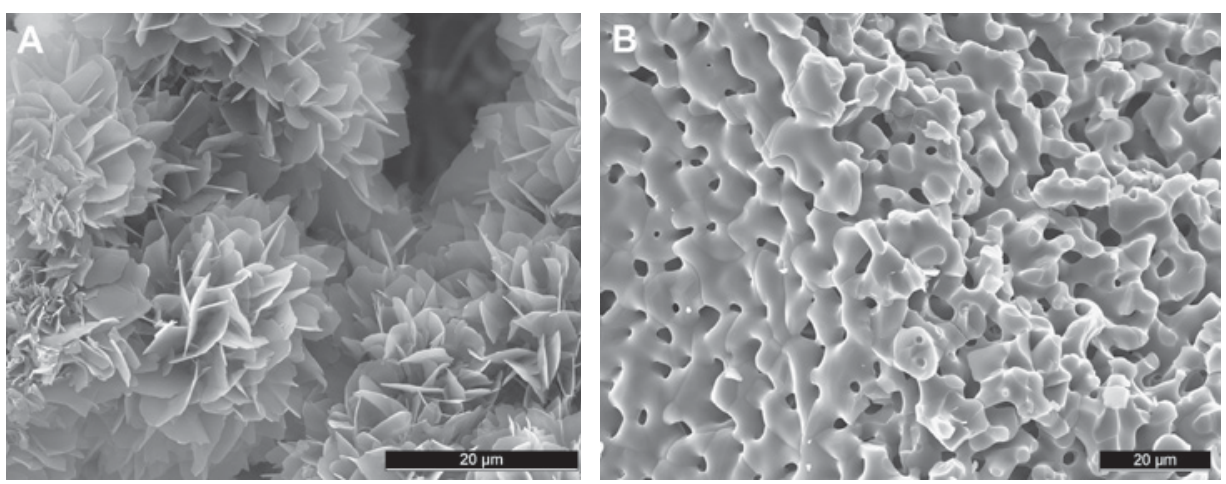

Fig. 1. Free crystal growth on the surface of precipitated calcium phosphate phases (A) produce specific surface areas up to two orders of magnitude higher than the smooth morphology of sintered materials $(\mathrm{B})$. 


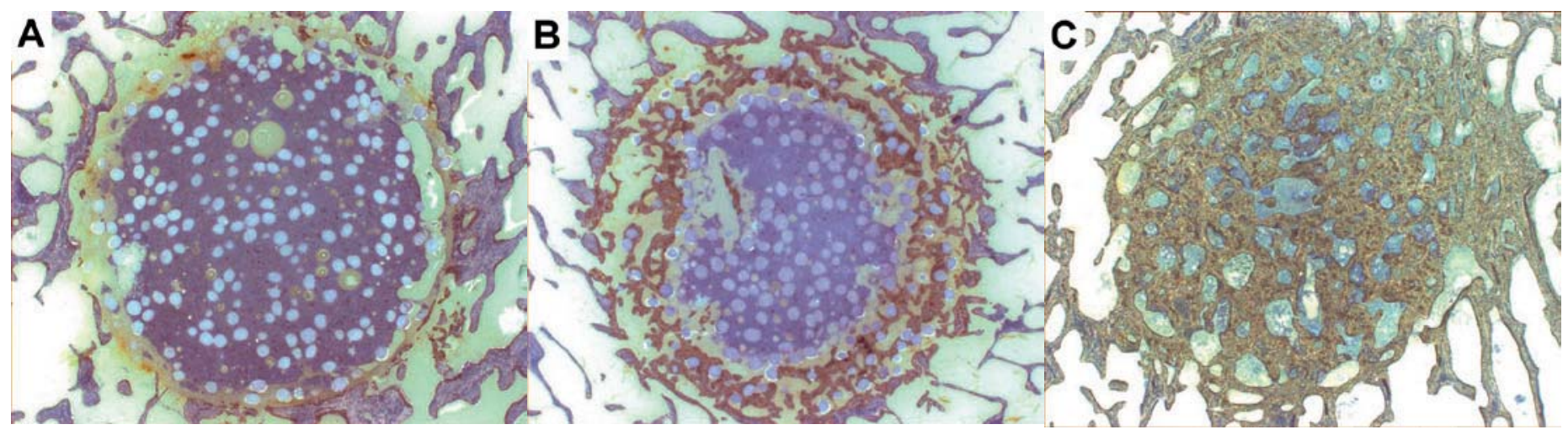

Fig. 2. A commercial DCPD cement with $\beta$-TCP granules (chronOs inject, Synthes) 2 weeks (A), 8 weeks (B), and 24 weeks (C) after implantation in a sheep. The DCPD matrix was partly dissolved after 8 weeks, and after 24 weeks the implant was completely replaced by new bone. Results of this animal study were published by Apelt et al..$^{[46]}$ and Theiss et al..$^{[4]]}$

High-temperature phases obtained from precursor ceramics thermally treated at temperatures typically above $500{ }^{\circ} \mathrm{C}$, on the other hand, show smooth surfaces and round particles due to sinter effects. Typical examples for high-temperature phases are sintered HA and $\beta$-TCP, both obtained above $500{ }^{\circ} \mathrm{C},{ }^{[42]}$ and $\alpha$-TCP forming above $1115{ }^{\circ} \mathrm{C} .{ }^{[43]}$ The precise temperatures of formation and phase transformation depend on the chemical purity and phase composition of the precursors. A phase diagram showing the stability fields of high-temperature calcium phosphate phases was published by Welsh. ${ }^{[44]}$

Thermal treatment of bone graft substitutes at temperatures above $700^{\circ} \mathrm{C}$ is attractive from a manufacturing point of view, as combustion of organic components is a very effective sterilization method. On the other hand, nano-crystalline low-temperature phases with high specific surface areas are more reactive and mimic the morphology of naturally formed bone mineral. It is assumed that these 'biomimetic' materials provoke a superior biological response in the bone defect, and eventually lead to faster resorption and formation of new bone than sintered materials. The decision for a low-temperature or a high-temperature phase is thus often, among others, also a decision for a simple sterilization process or a biomimetic surface.

\section{Biological Response to Synthetic Bone Void Fillers}

Ideally, the implant filling a defect dissolves at the same rate as new bone is formed. In healthy adult bone osteoblast and osteoclast activity are regulated and in equilibrium to maintain a constant bone mass. However, faster dissolution increasing the calcium concentration in the extracellular fluid at the resorption site can be used to signal high osteoclast activity, which triggers a reduction of osteoclast and an increase of osteoblast activity. ${ }^{[45]}$ Phases with a high solubility in vivo hence result in a higher bone formation rate and ultimately in a faster conversion of synthetic material into natural bone (Fig. 2).

The solubility at physiological $\mathrm{pH}$ $(\sim 7.4)$ is thus one of the principle parameters controlling the resorption rate of calcium phosphate bone graft substitutes. Based on data obtained from theoretical models, ${ }^{[48]}$ the following degradation rates were predicted: ${ }^{[49]} \mathrm{MCPM}>\mathrm{TetCP} \approx$ $\alpha$-TCP $>$ DCPD $>$ DCP $>$ OCP $>\beta$-TCP $>$ precipitated $\mathrm{HA}>$ sintered HA. Some readily soluble phases such as DCPD and OCP, however, tend to hydrolyze and gradually transform into HA. ${ }^{[50]}$ Cores of such implants can persist at the implant site in the form of non-resorbable particles surrounded by new bone. But the degradation rate observed in vivo is not only a function of solubility, it is also controlled to a large extent by geometrical factors such as a high specific surface area and an open micro- or macro-pore system. Moreover, a minimum aperture size of the pore interconnections of $100-200 \mu \mathrm{m}^{[51]}$ will allow fast vascularisation and give access for cells to the

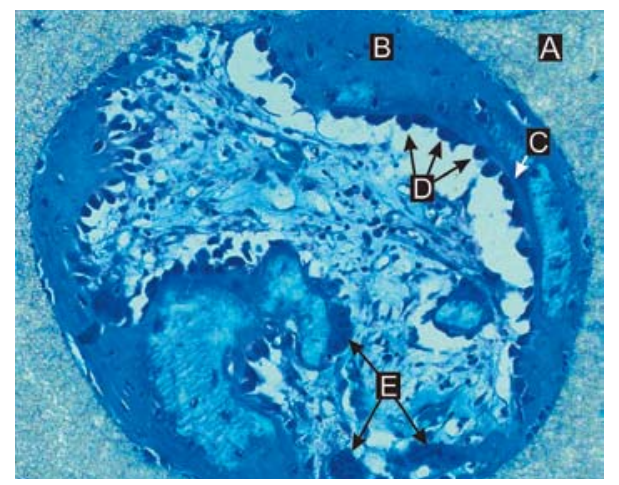

Fig. 3. A stained histology cross-section showing bone formation in a pore of a resorbable $\beta$-TCP implant. The size of the pore is approximately $0.5 \mathrm{~mm}$ in diameter. A: implant matrix; B: newly formed bone; C: osteoid; D: osteoblast cells; E: osteoclast cells. inner surface of the implant body (Fig. 3), which will vastly increase the degradation rate of the implant.

\section{Commercial Products}

The biological performance of a bone graft substitute is an important aspect in the development of a new commercial product. But as in every competitive market, there are a number of other aspects deciding on the commercial success of a product: Ease and cost of production, packaging and sterilization, and simple handling and application. Nowadays, most bone graft substitutes are applied in the form of granules, solid preforms, cements, putty pastes, or coatings on metal or polymer implants. Each form has its advantages and disadvantages, each of which will be discussed in the following sections. The indication is an important decisive criterion for the choice of a specific product or form of application. However, the final decision is often based on the size and shape of the defect to be filled, and to a large extent on the surgeon's personal preference and experience.

Granular bone void fillers are applicable in a wide range of orthopaedic and dental indications. Most products are available in particle sizes ranging from submillimetre to diameters of several millimetres. The inter-granular voids provide an open pore system allowing for fast vascularisation of the implant and rapid degradation of the particles. To further enhance the degradation rate, some products were designed to contain a specific macro- and micro-porosity within the particles (Fig. 4). When mixed with blood, granules form a mouldable paste fitting into cavities of any shape and size. However, application can be messy and particles getting into the surrounding tissue can hardly be avoided. Most products are recommended for filling of defects in non-load bearing situations in zones requiring cancellous rather 


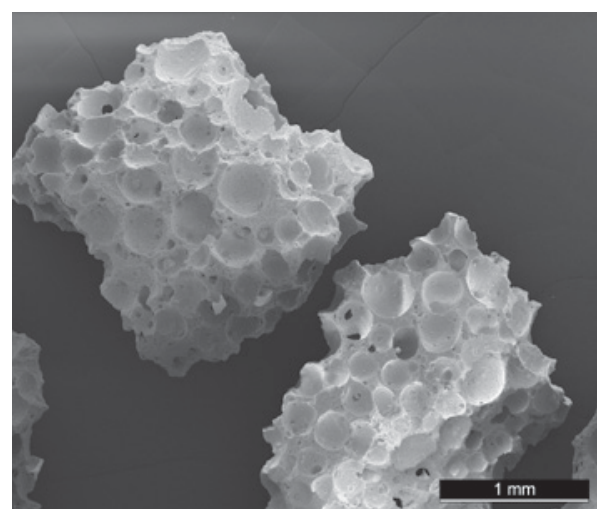

Fig. 4. Macro-porous $\beta$-TCP granules (Ceros, Mathys) allow for fast vascularisation and cell proliferation into the open pore system.

than cortical bone, including applications in trauma and orthopaedics, spinal surgery, and cranio-maxillofacial surgery. The majority of synthetic granular products available on the market these days are made of sintered phases such as $\beta$-TCP (e.g. Ceros - Mathys, ChronOS - Synthes, Cerasorb Curasan), HA (e.g. Osbone - Curasan), or bi-phasic mixtures of $\beta$-TCP and HA (e.g. $\mathrm{BCP}$ - Biomatlante). Promising results of recently published studies indicate that coming generations of granules will focus on more soluble phases such as DCPD and DCPA. [52,53]

Solid pre-forms are similar to granules in many ways: They are often made from the same phases and produced by similar manufacturing processes, they possess a well-defined open macroporosity, and they are usually recommended for similar indications. Unlike granules, pre-forms are sold in well-defined geometries, usually in the form of cylinders, square blocks, and wedges of various angles. Geometries are tailored for, but not limited to specific applications such as cylindrical burr holes, osteotomies with known angles and gap widths, or fillings of metal or polymer cages for spinal surgery. Most products are not designed for maximum mechanical strength. This allows the implants to be scraped and carved by the surgeon to match the shape and size of irregular defects.

So-called putties were developed in an attempt to combine the advantages of granules (filling of irregular defects) and preforms (clean handling) while at the same time avoiding the disadvantages (messy application of granules, regular defect shapes for pre-forms). In this relatively young generation of products granules mixed with a highly viscous hydrogel form a soft, ductile paste that can be pressed into a bone void without losing cohesion until the wound is closed. The hydrogel degrades quickly, leaving a highly porous granular implant. Application of putties is attractive due to the simplicity and the lack of time restrictions. On the other hand, limitations in reconstructive surgery are imposed by the fact that, unlike cements, the paste does not harden and remains structurally weak until bone formation creates mechanical strength. An example for non-setting putties is Ceros TCP putty (Mathys). The gap between non-setting putties and injectable cements is filled by hardening putties. These products are ductile and mouldable during application, but harden after a certain time due to a cement reaction. Examples for setting putties are CarriGen (Etex) and Norian SRS Fast Set Putty (Synthes).

Most calcium phosphate phases are reactive or soluble in aqueous media at neutral or acidic $\mathrm{pH}$. These properties have been used to develop hydraulic cements that are injected through a cannula into the bone defect, where the paste cures in situ and forms a solid spacer in the bone void. [54] There are several different types of setting reactions, including simple hydration reactions and dissolution-precipitation reactions. Secondary processes such as ionexchange and hydrolysis reactions may further affect the final composition of the cured cement.

Hydration reactions, as typically known from the reaction of plaster of Paris with water to solid gypsum, occur with reactive phases such as $\alpha-\mathrm{TCP}^{[55]}$ and mechanically activated DCPD. ${ }^{[56]}$ When mixed with water, these phases hydrate and mechanical interlocking and intergrowth of the crystals lead to hardening of the paste. The basic composition of this type of cement is very simple, consisting of only one powder phase and water. However, obtaining reactive phases requires high temperature $(\alpha$-TCP) or high kinetic energy (reactive DCPD), both rendering the manufacturing of raw materials expensive, and more additives may be necessary to control the reaction kinetics.

Dissolution-precipitation reactions are based on the concept of mixing a powder with a high $\mathrm{Ca}: \mathrm{P}$ ratio with a powder with a low Ca:P ratio or with phosphoric acid. The reaction forms a crystalline phase with an intermediate $\mathrm{Ca}: \mathrm{P}$ ratio. Common examples for this type of reaction are:

$$
\begin{aligned}
& \beta-\mathrm{TCP}+\mathrm{MCPM} \rightarrow \mathrm{DCPD}^{[57]} \\
& \beta-\mathrm{TCP}+\text { phosphoric acid } \rightarrow \mathrm{DCPD}^{[58,59]} \\
& \text { TetCP }+ \text { DCPD } \rightarrow \text { precipitated HA }
\end{aligned}
$$

Additives are often necessary to adjust the reaction kinetics, viscosity, injectability, and shelf life of the cement. Optional ingredients can be added to enhance X-ray contrast, porosity, resorption rate, and cell activity.

The advantages of an injectable cement are evident: i) Injection through a cannula allows for minimally invasive surgery only requiring a short incision, ii) the paste fills defects of irregular shape, iii) the paste gets in optimum contact and establishes a chemical bond with the host bone, and iv) the reaction products are similar to bone mineral in terms of crystallinity, specific surface area, mechanical properties, crystal size, and - depending on the formulation - in crystalline phase composition. However, despite these obvious advantages, most cements also have some inherent disadvantages: i) on a cellular and vascular scale most cured cements are dense due to the lack of an open system of macro-pores, ii) mixing and application must follow a strict schedule in order to avoid premature setting, iii) some products require complex and expensive mixing and injection devices, and iv) cement leakage from the defect can cause damage in the surrounding tissue. ${ }^{[62,63]}$ Several approaches to solve these problems and to simplify handling, devices, and composition are currently being worked on. ${ }^{64,65]}$ A critical review discussing the challenges researchers are facing when trying to fulfil the manufacturer's, the surgeon's, and the patient's requirements with a new product was published by Bohner et al. ${ }^{[66]}$ This publication also contains a list of commercial cements with information on vendor and phase composition.

Calcium phosphate cements can be used to fill a variety of bone defects originating from resections (tumours, cysts), autograft harvesting, burr holes, or osteotomies, or to establish a tight contact between metal implants and host bone. The latter may be necessary in cases of implant revision where large areas of the bone were damaged by removal of the old implant. Other applications include reconstructive maxillofacial, dental, and cranial surgery, as well as reinforcement of weak cancellous bone. Reinforcement may be required in situations where the cancellous bone is too weak to hold screws for internal fixations, for example in metaphyseal fractures of long bones or in osteoporotic bone. It is achieved by injecting the cement into the spongiosa to increase the density and mechanical stability. The same technique is also used to stabilize and support reconstructed compressive fractures such as compressed vertebra or tibial plateaus. ${ }^{67,68]}$

The strong bond between bone and calcium phosphate implants formed during the bone remodelling process can also be used to improve the fixation of metal implants in the bone. A coating of barely soluble calcium phosphate, typically HA, on the metal surface provides an interface to which bone can establish a strong chemical bond. The coating adheres to the metal substrate by mechanical interlocking. The most common process for deposition of a calcium phosphate layer on a metal sub- 
strate is plasma spray coating. ${ }^{[69]}$ Other approaches include precipitation from a solution forming a 'biomimetic' layer in a process similar to the formation of new bone, ${ }^{[70]}$ and electrochemical deposition. ${ }^{[71]}$ Calcium phosphate-coated metal implants are sold by most vendors of orthopaedic implants.

\section{Doping with Foreign lons}

It has been mentioned before that the mineral part of bone is not a chemically pure calcium phosphate, but that it contains a variety of other ions for which the bone serves as a reservoir and regulator to control their concentration in the body fluid. Nowadays, the effect of these trace elements on the bone remodelling process is one of the most actively researched subjects in the field of synthetic biomaterials. Besides the solubility and morphological features, trace elements are anticipated to be the third key to increasing cell activity and accelerating the integration and degradation of synthetic bone grafts. Most calcium phosphate phases can substitute a certain degree of $\mathrm{Ca}$ for other bivalent cations such as $\mathrm{Mg}, \mathrm{Sr}$, and $\mathrm{Zn}$ and also for mono- and trivalent ions such as $\mathrm{Li}, \mathrm{Na}$, $\mathrm{K}, \mathrm{Al}^{[72-74]}$ without undergoing a structural phase transformation. Similarly, phosphate can be substituted for silicate, ${ }^{[75]}$ sulphate and carbonate. ${ }^{[76,77]}$

Silicon ( $\mathrm{Si}$ ) has gained particular attention when it was shown that it occurs in higher concentrations in early stages of the calcification of young bone than in mature bone. ${ }^{[78]}$ The assumption that Si triggers faster bone formation by signalling the presence of young bone has led to a rush towards Si-doped calcium phosphate bone substitutes. However, despite a large part of the scientific community being optimistic about the superior performance of Sidoped implants, the ultimate proof that the higher bone turnover is a primary effect of $\mathrm{Si}$ ions is still lacking. Instead, the high cell activity could also be explained by faster release of $\mathrm{Ca}$ and $\mathrm{P}$ as a result of increased solubility of Si-doped phases as compared to chemically pure ones. ${ }^{[79]}$

Ionic substitution in resorbable synthetic bone substitutes is an efficient method to deliver therapeutic doses of foreign ions to the bone. The most prominent example is the delivery of strontium (Sr) in treatment of osteoporotic bone. $\mathrm{Sr}$ stimulates osteoblast and suppresses osteoclast activity and thus increases the density and strength of new bone at the site of delivery by rebalancing the bone turnover in favour of bone formation. ${ }^{[80]}$ Manufacturing processes and the physico-chemical properties of resorbable ceramics as a host for controlled delivery of trace ele- ments have been investigated thoroughly for more than a decade, but the number of Sr-releasing synthetic bone graft substitutes actually available on the market is surprisingly low. The reason could be that there is no demand for such a product. More common than local delivery at the implant site is the oral administration of a suspension of $\mathrm{Sr}$ ranelate, an $\mathrm{Sr}$ salt of ranelic acid which is generally well tolerated and successfully used in systemic treatment of postmenopausal osteoporosis. ${ }^{[81]}$

Besides therapeutic or marketing-related interests, ionic substitutions are used to control various physico-chemical properties of calcium phosphate materials. A large number of publications describe the effect of trace elements on thermal stability, solubility, mechanical stability, densification, crystal size and morphology, reactivity, surface topography, and reaction kinetics of cements, just to name a few. On the other hand, commercial manufacturers of medical devices are faced with increasingly complex and demanding regulatory hurdles and are thus reluctant towards additives, especially if they add complexity to a product without yielding a significant benefit. This may be one of the many reasons why only a limited number of the results from academic research projects are picked up and brought to the market by manufacturers of medical devices.

\section{Outlook}

The osteoconductive and -inductive capacity of synthetic bone graft substitutes can be vastly increased by addition of proteins such as bone morphogenic proteins (BMP), activin, or transforming growth factor- $\beta$ (TGF- $\beta$ ). However, drug-free synthetic bone graft substitutes are classified as class II or class III medical devices, which, according to the US Federal Food, Drug, and Cosmetic Act (FD\&C Act) are defined as: “(..) an instrument, apparatus, implement, machine, contrivance, implant, in vitro reagent, or other similar or related article, including any component, part, or accessory, which is (...) intended to affect the structure or any function of the body of man or other animals, and which does not achieve its primary intended purposes through chemical action within or on the body of man or other animals and which is not dependent upon being metabolized for the achievement of its primary intended purposes." Pharmaceutical drugs and medical devices need to be approved by the notified body before legally entering a market. The requirements for a drug to obtain approval are much higher and hence more expensive and more time con- suming than for a medical device. There is thus an economic interest for manufacturers not to combine synthetic bone graft substitutes with active substances. Trying to improve osteoconductivity and to obtain osteoinductive calcium phosphate implants purely by optimizing the composition and geometrical features will thus remain one of the major challenges for scientists and manufacturers in the near future.

All resorbable ceramic implants on the market these days, regardless of shape and composition, share one major drawback: They are brittle and not suitable for loadbearing applications without reinforcing metal plates. It is questionable whether purely ceramic materials will ever fulfil all requirements in terms of toughness, porosity, solubility, and biocompatibility for a perfect load-bearing bone void filler. This gap between brittle but degradable ceramics and tough but persistent metal implants will most likely be filled by composite materials combining a ceramic component for hardness, and a polymer part for toughness. ${ }^{[82]}$ As discussed at the beginning of this article, there are numerous examples for such materials in Nature, including in our immediate environment and even in our own bodies, and it remains the scientist's challenge to observe, to learn to understand, and to reproduce Nature's amazing achievements.

Received: June 28, 2010

[1] R. V. Baudinette, K. Schmidt-Nielsen, Nature 1974, 248, 83 .

[2] D. W. Bechert, M. Bruse, W. Hage, Exper. Fluids 2000, 28, 403.

[3] W. Barthlott, C. Neinhuis, Planta 1997, 202, 1.

[4] H. Lee, B. P. Lee, P. B. Messersmith, Nature 2007, 448, 338.

[5] J. McKittrick, P.-Y. Chen, L. Tombolato, E. E. Novitskaya, M. W. Trim, G. A. Hirata, E. A. Olevsky, M. A. Meyers, M. F. Horstmeyer, Mater. Sci. Eng. C 2010, 30, 331.

[6] J. A. Buckwalter, M. J. Glimcher, R. R. Cooper, R. Recker, Instr. Course Lect. 1996, 45, 387.

[7] E. Munch, M. E. Launey, D. H. Alsem, E. Saiz, A. P. Tomsia, R. O. Ritchie, Science 2008, 322, 1516.

[8] A. S. Posner, Clin. Orthop. 1985, 200, 87.

[9] S. Weiner, H. D. Wagner, Ann. Rev. Mater. Sci. 1998, 28, 271.

[10] L. P. Gartner, J. L. Hiatt, 'Color Textbook of Histology', W.B. Saunders Company, Philadelphia, Pennsylvania 19106, 1997.

[11] S. L. Teitelbaum, Science 2000, 289, 1504.

[12] P. Ducy, T. Schinke, G. Karsenty, Science 2000, 289, 1501.

[13] I. A. Silver, R. J. Murrills, D. J. Etherington, Exp. Cell Res. 1988, 175, 266.

[14] C. Minkin, V. C. Marinho, Adv. Dent. Res. 1999, 13, 49.

[15] W. E. Brown, Clin Orthop 1966, 44, 205

[16] M. J. Glimcher, Rev. Modern Phys. 1959, 31, 359.

[17] A. S. Posner, F. Betts, Acc. Chem. Res. 1975, 8, 273.

[18] J. A. Buckwalter, M. J. Glimcher, R. R. Cooper, R. Recker, J. Bone Joint Surg. 1995, 77 A, 1256. 
[19] M. J. Glimcher, L. C. Bonar, M. Grynpas, W. J. Landis, A. H. Roufosse, J. Crys. Growth 1981, 53, 100 .

[20] M. S. Johnsson, G. H. Nancollas, Crit. Rev Oral Biol. Med. 1992, 3, 61 .

[21] M. J. Olszta, X. Cheng, S. S. Jee, R. Kumar, Y.-Y. Kim, M. J. Kaufman, E. P. Douglas, L. B. Gower, Mater. Sci. Eng. R 2007, 58, 77.

[22] C. G. Finkemeier, J. Bone Joint Surg. Amer. 2002, 84A, 454.

[23] E. M. Younger, M. W. Chapman, J. Orthop Trauma 1989, 3, 192.

[24] J. C. Banwart, M. A. Asher, R. S. Hassanein, Spine 1995, 20, 1055.

[25] C. J. Damien, J. R. Parsons, J. Appl. Biomater. $1991,2,187$.

[26] C. Laurencin, Y. Khan, S. F. El-Amin, Expert Rev. Med. Dev. 2006, 3, 49 .

[27] H. Dreesmann, Beitr. Klin. Chir. 1892, 9, 804.

[28] G. Nystrom, Acta Chir. Scand. 1928, 63, 296.

[29] E. Edberg, Acta Chir. Scand. 1930, 67, 313.

[30] H. Albee, S. J. Morrison, Ann. Surg. 1920, 71, 32.

[31] M. D. Haldeman, J. M. Moore, Arch. Surg. 1934, 385.

[32] W. J. Stewart, Gyn. Obst. Surg. 1934, 59, 867.

[33] D. E. Cutright, S. N. Bhaskar, J. M. Brady, L. Getter, W. R. Posey, Oral Surg. Oral Med. Oral Pathol. 1972, 33, 850.

[34] L. Getter, N. S. Bhaskar, D. E. Cutright, B. Perez, J. M. Brady, T. D. Driskell, M. J. O'Hara, J. Oral Surg. 1972, 30

[35] T. Driskell, J. Dental Res. 1973, 52, 123.

[36] K. Köster, E. Karbe, H. Kramer, H. Heide, R. König, Langenbecks Arch. Chir. 1976, 341, 77.

[37] H. U. Cameron, I. Macnab, R. M. Pilliar, J. Biomed. Mater. Res. 1977, 11, 179.

[38] A. M. Gatti, D. Zaffe, G. P. Poli, Biomaterials 1990, 11, 513.

[39] M. Bohner, F. Theiss, D. Apelt, W. Hirsiger, R. Houriet, G. Rizzoli, E. Gnos, C. Frei, J. A Auer, B. von Rechenberg, Biomaterials 2003, 24, 3463.

[40] S. Kamakura, Y. Sasano, T. Shimizu, K. Hatori, O. Suzuki, M. Kagayama, K. Motegi, J. Biomed. Mater. Res. 2002, 59, 29.

[41] L. G. Galea, M. Bohner, J. Lemaitre, T. Kohler, R. Muller, Biomaterials 2008, 29, 3400.

[42] S. Somrani, C. Rey, M. Jemal, J. Mater. Chem. 2003, 13, 888 .

[43] R. G. Carrodeguas, A. H. De Aza, X. Turrillas, P. Pena, S. De Aza, J. Amer. Ceramic Soc. 2008, $91,1281$.
[44] J. H. Welch, W. Gutt, J. Chem. Soc. 1961, 874, 4442.

[45] M. Kanatani, T. Sugimoto, M. Fukase, T. Fujita, Biochem. Biophys. Res. Commun. 1991, 181, 1425.

[46] D. Apelt, F. Theiss, A. O. El-Warrak, K. Zlinszky, R. Bettschart-Wolfisberger, M. Bohner, S. Matter, J. A. Auer, B. von Rechenberg, Biomaterials 2004, 25, 1439.

[47] F. Theiss, D. Apelt, B. Brand, A. Kutter, K. Zlinszky, M. Bohner, S. Matter, C. Frei, J. A. Auer, B. von Rechenberg, Biomaterials 2005, $26,4383$.

[48] G. Vereecke, J. Lemaitre, J. Crys. Growth 1990 , 104,820 .

[49] M. Bohner, Injury 2000, 31 Suppl 4, 37.

[50] L. M. Grover, J. C. Knowles, G. J. P. Fleming, J. E. Barralet, Biomaterials 2003, 24, 4133.

[51] M. Bohner, F. Baumgart, Biomaterials 2004, 25, 3569.

[52] F. M. Tamimi, J. Torres, I. Tresguerres, L. J. Blanco, E. Lopez, J. Biomed. Mater. Res. A 2007, 81A, 93.

[53] F. Tamimi, J. Torres, C. Kathan, R. Baca, C. Clemente, L. Blanco, E. Lopez Cabarcos, J. Biomed. Mater. Res. A 2008, 87, 980.

[54] A. A. Mirtchi, J. Lemaitre, N. Terao, Biomaterials 1989, 10, 475 .

[55] M. Bohner, R. Luginbuhl, C. Reber, N. Doebelin, G. Baroud, E. Conforto, Acta Biomater. 2009, 5, 3524.

[56] A. Tofighi, Key Eng. Mater. 2009, 396-398, 281.

[57] P. Van Landuyt, C. Lowe, J. Lemaitre, Bioceramics 1997, 10, 477.

[58] J. Lemaitre, H. Andrianjatovo, C. Biourge, K. Ohura, P. Harodouin, Oberflächen Werkstoffe 1994, 9, 13.

[59] M. Bohner, J. Lemaitre, T. A. Ring, in 'Hydraulic properties of $\beta$-TCP - H3PO4 - H2O mixtures', Third Euroceramics, Madrid, 1993, Eds. P. Duran, J. F. Fernandez, Faenza Editrice Iberica SL: Madrid, 1993, pp 95.

[60] E. Mejdoubi, A. Garbarsky, J. L. Lacout, Sulfur and Phosphorus 1993, 77, 284.

[61] W. E. Brown, L. C. Chow, J. Dental Res. 1983, $62,672$.

[62] E. P. Lin, S. Ekholm, A. Hiwatashi, P. L. Westesson, AJNR Am. J. Neuroradiol. 2004, 25, 175.

[63] J. S. Yeom, W. J. Kim, W. S. Choy, C. K. Lee, B. S. Chang, J. W. Kang, J. Bone Joint Surg. Br. 2003, 85, 83.

[64] L. M. Grover, S. Patel, Y. Hu, U. Gbureck, J. Barralet, Key Eng. Mater. 2008, 361-363, 311.
[65] S. Takagi, L. C. Chow, S. Hirayama, A. Sugawara, J. Biomed. Mater. Res. 2003, 67B, 689.

[66] M. Bohner, U. Gbureck, J. E. Barralet, Biomaterials 2005, 26, 6423 .

[67] S. Larsson, T. W. Bauer, Clin. Orthop. 2002 , 395, 23.

[68] S. Larsson, Scan. J. Surg. 2006, 95, 111.

[69] B. Koch, J. G. Wolke, K. de Groot, J. Biomed. Mater. Res. 1990, 24, 655.

[70] F. Barrere, P. Layrolle, B. C. A. Van, G. K. de, Bioceramics 1999, 12, 125.

[71] M. Kumar, H. Dasarathy, C. Riley, J. Biomed. Mater. Res. 1999, 45, 302.

[72] K. Yoshida, N. Kondo, H. Kita, M. Mitamura, K. Hashimoto, Y. Toda, J. Amer. Ceramic Soc. 2005, 88, 2315.

[73] K. Yoshida, H. Hyuga, N. Kondo, H. Kita, M. Sasaki, M. Mitamura, K. Hashimoto, Y. Toda, J. Amer. Ceramic Soc. 2006, 89, 688.

[74] A. Bigi, E. Foresti, M. Gandolfi, M. Gazzano, N. Roveri, J. Inorg. Biochem. 1997, 66, 259.

[75] M. Sayer, A. D. Stratilatov, J. Reid, L. Calderin, M. J. Stott, X. Yin, M. MacKenzie, T. J. Smith, J. A. Hendry, S. D. Langstaff, Biomaterials 2003, 24, 369

[76] M. Bohner, N. Doebelin, Eur. Cells Mater. 2006, 11,16 .

[77] D. McConnell, Amer. Mineral. 1937, 22, 977.

[78] E. M. Carlisle, Science 1970, 167, 279.

[79] M. Bohner, Biomaterials 2009, 30, 6403.

[80] P. J. Marie, P. Ammann, G. Boivin, C. Rey, Calcif. Tissue Int. 2001, 69, 121.

[81] E. D. Deeks, S. Dhillon, Drugs 2010, 70, 733.

[82] L. J. Bonderer, A. R. Studart, J. Woltersdorf, E. Pippel, L. J. Gauckler, J. Mater. Res. 2009, 24, 2741. 